\title{
Effect of Moisture in a Vacuum Chamber on the Deposition of c-BN Thin Film using an Unbalanced Magnetron Sputtering Method
}

\author{
Eun-Sook Lee, Jong-Keuk Park, Wook-Seong Lee, Tae-Yeon Seong*, and Young-Joon Baik ${ }^{\dagger}$
}

Electronic Materials Center, Korea Institute of Science and Technology, Seoul 136-793, Korea

*Department of Materials Science \& Engineering, Korea University, Seoul 133-791, Korea

(Received August 9, 2012; Revised November 5, 2012; Accepted November 12, 2012)

\section{비대칭 마그네트론 스퍼터링 방법에 의한 질화붕소막의 증착시 반응실내의 초기 수분이 입방정질화붕소 박막의 형성에 미치는 영향}

\author{
이은숙 · 박종극 · 이욱성 · 성태연 * 백영준 \\ 한국과학기술연구원 전자재료센터 \\ *고려대학교 신소재공학과
}

(2012년 8월 9일 접수 ; 2012년 11월 5일 수정 ; 2012년 11월 12일 채택)

\begin{abstract}
The role of moisture remaining inside the deposition chamber during the formation of the cubic boron nitride (c-BN) phase in BN film was investigated. BN films were deposited by an unbalanced magnetron sputtering (UBM) method. Single-crystal (001) Si wafers were used as substrates. A hexagonal boron nitride (h-BN) target was used as a sputter target which was connected to a $13.56 \mathrm{MHz}$ radiofrequency electric power source at $400 \mathrm{~W}$. The substrate was biased at $-60 \mathrm{~V}$ using a $200 \mathrm{kHz}$ high-frequency power supply. The deposition pressure was $0.27 \mathrm{~Pa}$ with a flow of $\mathrm{Ar} 18 \mathrm{sccm}-\mathrm{N}_{2} 2 \mathrm{sccm}$ mixed gas. The inside of the deposition chamber was maintained at a moisture level of $65 \%$ during the initial stage. The effects of the evacuation time, duration time of heating the substrate holder at $250^{\circ} \mathrm{C}$ as well as the plasma treatment on the inside chamber wall on the formation of c-BN were studied. The effects of heating as well as the plasma treatment very effectively eliminated the moisture adsorbed on the chamber wall. A pre-deposition condition for the stable and repeatable deposition of c-BN is suggested.
\end{abstract}

Key words : Boron nitride, Thin films, Water, Absorption, Heat treatment

\section{1. 서 론}

입방정질화붕소 (cubic boron nitride: c-BN)는 다이아몬 드에 버금가는 경도와 열전도도를 가지고 있으며 다이아 몬드와는 달리 고온에서의 철 계 금속과의 반응성이 매 우 작고, 내산화성이 우수하여 내 마모 박막재료의 아주 훌륭한 후보 재료이다. 또한 밴드갭이 크고, 전자 및 홀 의 높은 이동도 및 $\mathrm{n}$ 형, $\mathrm{p}$ 형의 doping이 가능하여 고온, 고출력 반도체 재료로의 응용 가능성도 매우 큰 재료이 다. ${ }^{1)}$ 이러한 우수한 물성을 활용하기 위해서는 원하는 물 성의 원하는 형태로의 합성이 가능하여야 한다.

c-BN은 자연계에 존재하지 않는 물질로 다이아몬드와 유사한 열역학적 특징을 갖는다. 다이아몬드가 상온 상압

\footnotetext{
${ }^{\dagger}$ Corresponding author : Young-Joon Baik

E-mail : yjbaik@kist.re.kr

Tel : +82-2-958-5493 Fax : +82-2-958-5509
}

에서 흑연에 비해 불안정하듯이 c-BN도 육방정질화붕소 (hexagonal boron nitride: h-BN)에 비해 상온 상압에서 불 안정한 물질이다. 따라서 공업적으로 사용되고 있는 c-BN 의 합성은 고온고압법에 의해 이루어지고 있다. 1980년 이후로 c-BN을 박막형태로 합성하기 위한 시도가 많이 진행되어 현재 실험적으로 다양한 증착공정이 확립되어 c-BN이 박막형태로 합성이 되고 있으나, 모재와의 밀착 력에 많은 문제를 가지고 있어 응용은 이루어지고 있지 않다. ${ }^{2)}$

c-BN의 기상합성에 있어 중요한 문제 중의 하나는 합 성 중 혼입된 불순물에 매우 취약하다는 것이다. 증착 시 작 전에 반응조의 초기 진공도가 c-BN 상의 형성에 큰 영향을 준다는 것이 보고되고 있으며, ${ }^{3)}$ 산소와 수소의 혼 입 역시 c-BN의 형성에 영향을 미치는 것으로 보고되어 있다. ${ }^{4,5)}$ 따라서 반응조 내의 환경이 매우 중요하게 된다.

반응조를 대기 중에 노출시키게 되면, 대기 중의 수분, 질 소, 산소, 탄화수소 등이 반응조 내벽에 흡착되게 된다.) 
앞서 설명하였듯이 이들 중, c-BN의 형성에 영향을 줄 수 있는 것으로 수소와 산소를 들 수 있는데, 특히 수분의 경우는 c-BN의 형성을 방해하는 수소와 산소로 이루어져 반응조 내의 잔류하고 있는 수분의 제어가 매우 중요함 을 예상할 수 있다. 본 연구에서는 반응조 내에 수분을 의도적으로 흡착시키고, 수분의 흡착이 c-BN의 형성에 미 치는 영향을 살펴보려 하였다. 이로부터 c-BN의 합성에 있어 반응조 내의 잔류물의 영향을 배제시킬 수 있는 조 건을 제시하려 하였다.

\section{2. 실험 방법}

비대칭 마그네트론 (UBM, Unbalanced magnetron) 스퍼 터링 방법을 이용하여 $\mathrm{BN}$ 박막을 증착하였다. 스퍼터링 타겟과 기판지지대는 서로 마주 보고 있는 구조를 가지 고 있고, 이들 간의 간격은 $7.5 \mathrm{~cm}$ 로 고정하였다. 기판은 $\mathrm{Si}$ (100)을 사용하였고, 스퍼터 타겟은 $99.5 \%$ 순도를 갖 는 지름 $2 "$, 두께 0.25 "의 원형 판 형태의 h-BN 타겟을 사용하였다. 증착 기체는 아르곤 $18 \mathrm{sccm}$, 질소 $2 \mathrm{sccm}$ 의 혼합기체였고, 증착 압력은 $4 \mathrm{mTorr}$ 로 유지하였다. 타겟의 스퍼터링을 위하여 $13.56 \mathrm{MHz}$ 의 $\mathrm{RF}$ 전원을 사용하였는 데, $400 \mathrm{~W}$ 의 전력을 인가하였다. 기판 바이어스인가를 위 하여 고주파 $200 \mathrm{kHz}$ 전원을 사용하여 $-60 \mathrm{~V}$ 의 self-bias 를 유도하였다. 증착시간은 대부분의 경우 20 분이었다. 반 응조의 가열에 사용한 $\mathrm{SiC}$ 발열체는 기판지지대 하부에 위치하였으며, 온도는 $\mathrm{R}$ 형의 열전대를 기판 지지대 하부 에 접촉시켜 측정하였다.

반응조 내벽에 인위적으로 수분을 흡착시키기 위하여 습도계로 습도를 측정하면서 수분을 반응조 내부에서 증 발시켜 일정 습도가 되면 수분의 투입을 중단하는 방법 을 사용하였다. 본 연구에서는 반응조 내부에서의 습도를 $65 \%$ 로 고정하였다.

수분의 영향을 보기 위하여 선택한 변수는 배기 시간, 반응조의 가열 그리고 증착 시 플라즈마와 반응조 내벽 과의 접촉 효과이었다. 배기 시간의 영향을 보기 위하여 상온에서 반응조를 turbo molecular pump로 배기하며 배 기 시간을 변화시켰고, 반응조의 가열 효과는 반응조의 발열체를 기판지지대의 온도가 $250^{\circ} \mathrm{C}$ 가 되도록 가열하고 진공 배기를 하면서 가열 시간을 변화시켰다. 일정시간 가열 후 기판부를 상온으로 냉각하고 load lock 장치를 이 용하여 반응조의 진공을 깨지 않은 상태로 시편을 장입 하여 증착을 시도하였고, 증착이 끝난 후에 다시 load lock 장치를 이용하여 시편을 제거하였다. 그 후 다시 기판지 지대의 온도를 가열하는 공정과 같은 방법으로 증착을 시 도하는 방법을 반복하였다. 마지막으로 플라즈마와의 접 촉 영향을 보기 위하여, 증착 중 플라즈마와 반응조 내벽 이 접촉을 하므로 증착횟수의 변화로 플라즈마와의 접촉
의 영향을 살펴보았다. 이 경우도 가열 시험과 마찬가지 로 플라즈마 처리 후 load lock 장치를 이용하여 시편을 장입하여 증착한 후 시편을 제거하고 플라즈마 처리를 진 행하는 과정으로 실험을 진행하였다. 모든 경우 증착을 시작하기 전에 30 분간 진공 배기를 한 후 증착을 시작하 였다.

증착된 $\mathrm{BN}$ 박막은 적외선 분광분석법 (FTIR, Perkin Elmer Spectrum Frontier)을 이용하여 c-BN 상과 h-BN 상의 형성 유무 및 분율을 평가하였다. BN 박막의 FTIR spectrum 에서 3 개의 중요한 흡수픽이 관찰되는데, $780 \mathrm{~cm}^{-1}$ (out of plane B-N-B bending)과, $1380 \mathrm{~cm}^{-1}$ (in-plane B-N stretching) 부근의 흡수는 $\mathrm{h}-\mathrm{BN}$ 상에 기인하고, $1080 \mathrm{~cm}^{-1}$ 의 흡수선은 $\mathrm{c}-\mathrm{BN}$ 상에 기인한다. $\mathrm{BN}$ 박막 내 $\mathrm{c}-\mathrm{BN}$ 상의 분율은 FTIR 흡수픽의 강도를 측정하여 다음 식을 이용하여 계 산 된다. ${ }^{7)}$

c-BN fraction in $\mathrm{BN}$ film $=\left[\mathrm{I}_{1080} /\left(\mathrm{I}_{1080}+\mathrm{I}_{1380}\right)\right] \times 100$

\section{3. 결과 및 고찰}

Fig. 1은 반응조를 대기 중에 노출시킨 경우와 반응조 의 습도를 $65 \%$ 로 안정화 시킨 다음 진공 펌프로 배기할 경우 배기 시간에 따른 반응조의 진공도 변화를 보여준 다. 이 경우 대기 중의 습도는 약 $35 \%$ 로 측정되었다. 반 응조의 압력 강하 속도는 시간에 따라 감소하고 있음을 알 수 있고, 두 경우에 감소속도는 확연한 차이를 보임을 알 수 있다. 이러한 차이로부터 반응조 내부에 흡착된 주 요 물질이 수분임을 알 수 있다. 그래프의 변화 거동으로 볼 때 상온에서 떨어질 수 있는 압력은 특정 값에 접근 함을 예상할 수 있고, 배기 시간을 늘리는 방법으로는 압 력을 낮추는 것에 한계가 있음을 알 수 있다.

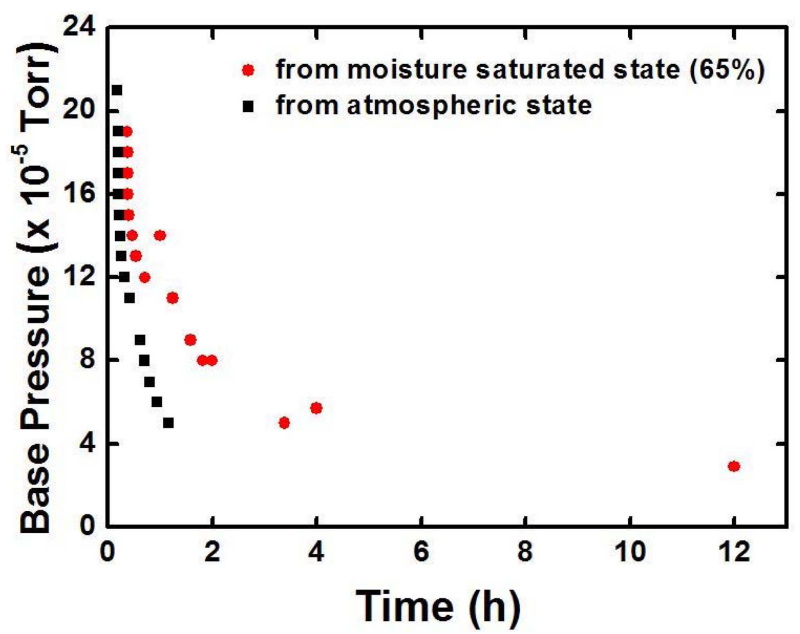

Fig. 1. Effect of evacuation time on the chamber pressure according to the initial moisture level inside the chamber. 
보통 고체 표면의 흡착은 물리적 흡착과 화학적 흡착 으로 나뉘어진다. 물리적 흡착의 경우 Van der Waals 힘 이 작용하여 진공 배기 시 용이하게 탈착이 일어나서 반 응조에서 쉽게 제거할 수 있다. 반면에 화학적 흡착의 경 우 탈착에 필요한 에너지가 매우 커서 상온에서의 탈착 이 매우 어렵다. 화학적 탈착의 경우 탈착 속도는 다음 식으로 나타내어진다. ${ }^{6}$

$$
\mathrm{dC}(\mathrm{t}) / \mathrm{dt}=\mathrm{C}_{\mathrm{o}} \mathrm{Ke}^{-\mathrm{t} / \tau_{\mathrm{r}}}
$$

여기서 $\mathrm{C}, \mathrm{K}, \tau_{\mathrm{r}}$ 은 각각 first order desorption, 속도상 수, 흡착입자의 진동수이다. 탈착속도가 시간이 지남에 따 라 점점 작아지므로 배기속도도 시간에 따라 점점 감소 하게 되므로 Fig. 1과 같은 거동이 관찰된다.

잔류하고 있는 수분의 최대량은 이상기체 방정식을 이 용하여 간단히 추산할 수 있다. 초기 반응조에 있는 기체 는 질소와 산소이고 이것은 용이하게 배출된다. 또한 반 응조 내벽에 물리적으로 흡착된 기체 또한 용이하게 배 출된다. 따라서 Fig. 1에서와 같이 배기 시간이 지나도 반 응조에 잔류하고 있는 기체의 대부분은 반응조 내벽에서 탈착된 수분이라 가정할 수 있다. 이때의 이상기체 방정 식은 아래와 같다.

$$
\mathrm{P}_{1} \mathrm{~V}=\mathrm{n}_{1} \mathrm{RT}
$$

여기서 $\mathrm{P}_{1}, \mathrm{n}_{1}$ 은 각각 배기 중 반응조의 압력과 잔류하 고 있는 수분의 mole수이고, $\mathrm{V}, \mathrm{R}, \mathrm{T}$ 는 반응조의 부피, 이 상기체 상수, 반응조 내부 기체의 온도이다. 증착 시 반 응조의 이상기체방정식은 다음과 같이 유사하게 나타낼 수 있다.

$$
\mathrm{P}_{2} \mathrm{~V}=\left(\mathrm{n}_{1}+\mathrm{n}_{\mathrm{Ar}}+\mathrm{n}_{\mathrm{N} 2}\right) \mathrm{RT}
$$

여기서 $\mathrm{P}_{2}, \mathrm{n}_{\mathrm{Ar}}, \mathrm{n}_{\mathrm{N} 2}$ 는 각각 증착압력, 반응기체인 $\mathrm{Ar}$ 과 질소의 mole수이다. 두 식을 정리하면

$$
\mathrm{n}_{1} /\left(\mathrm{n}_{1}+\mathrm{n}_{\mathrm{Ar}}+\mathrm{n}_{\mathrm{N} 2}\right)=\mathrm{P}_{1} / \mathrm{P}_{2}
$$

와 같이 되며 이 식은 반응조의 부피나 기하학적인 형상 에 무관하므로 간단하게 사용할 수 있음을 알 수 있다. 두 경우 압력의 비는 $10^{-2} \sim 10^{-3}$ 범위이므로 증착 시 반응조 내부의 수분의 양은 $1 \sim 0.1 \%$ 범위에 해당된다. 한편 수 소나 산소를 반응기체에 첨가하는 경우 반응기체에 수소 나 산소가 수 $\%$ 정도 되면 c-BN 상의 형성에 방해를 주 게 된다. ${ }^{4,5}$ 이전 보고 결과의 c-BN 상의 형성을 방해하 는 산소와 수소의 양을 이용하여, ${ }^{4,5)}$ 계산해 보면, 위의 식 에서 계산된 수분의 함량이 c-BN의 형성에 영향을 줄 수
있는 수소나 산소의 양에 비해 약 $1 / 10$ 배 정도 되는 것으 로 나타난다. 이러한 차이는 수분이 분해되면 수소 원자, 산소 원자 그리고 $\mathrm{OH}$ 결함 원소로 구성되므로 이들의 영 향이 수소나 산소가 단독으로 존재했을 때의 영향보다 크 게 나타날 수 있는 가능성에 기인할 것으로 생각된다. 따 라서 계산 오차 등의 가능성을 고려하면, 반응조의 잔류 수분이 충분히 c-BN 형성에 영향을 미칠 수 있는 수준 범위에 있다고 판단된다.

반응조를 일정시간 배기한 후 $\mathrm{BN}$ 막을 증착하였다. 사 용한 증착 조건은 기판 bias가 $-60 \mathrm{~V}$ 로 c-BN 상이 잘 형 성되는 조건이었다. Fig. 2는 배기시간에 따라 증착된 박 막의 FTIR 스펙트럼의 변화를 보여준다. 각 그래프에 배 기 후 반응조의 압력을 표시하였다. 그런데 Fig. 2의 스 펙트럼에서는 h-BN 흡수픽들만 관찰되고 있다. 따라서 12 시간 배기 후에도, 진공조의 압력이 $10^{-6} \mathrm{Torr}$ 부근에 도 달하였음에도 불구하고 반응조의 내부 분위기가 c-BN 형 성에 적합하지 않음을 알 수 있다.

진공조 내부에 흡착된 수분의 경우 고체 표면에 잔류 하는 시간은 온도에 크게 의존한다. 일례로 금속벽에 흡 착된 수분의 잔류시간이 $22^{\circ} \mathrm{C}$ 에서 $10^{5} \mathrm{sec}$ 인데 반하여 $450^{\circ} \mathrm{C}$ 에서는 $10^{-5} \mathrm{sec}$ 으로 크게 줄어든다. ${ }^{6}$ 따라서 온도증 가에 의해 탈착이 매우 빠르게 진행됨을 알 수 있다. 수 분의 경우 금속 벽에 화학적으로 흡착되게 되는데 이 경 우 상온에서는 탈착이 매우 어렵고 $250 \sim 300^{\circ} \mathrm{C}$ 의 가열로 수분의 잔류시간을 크게 줄여 용이하게 탈착시킬 수 있 다. ${ }^{6}$ 이러한 효과를 이용하여 배기를 용이하게 하기 위하 여 기판부의 온도를 $250^{\circ} \mathrm{C}$ 로 올린 후 반응조의 배기를 수 행하면서 일정시간 유지하였다. 이때 반응조 내부 벽의 온도는 정확히 측정할 수 없었고, 반응조 외벽은 수냉이 되게 장비가 구성이 되어, 반응조 내벽의 실제 온도는 현 저히 낮을 것으로 추정된다. Fig. 3 은 $250^{\circ} \mathrm{C}$ 에서 일정시 간 유지하고 상온에서 30 분간 배기 한 후 측정한 반응조

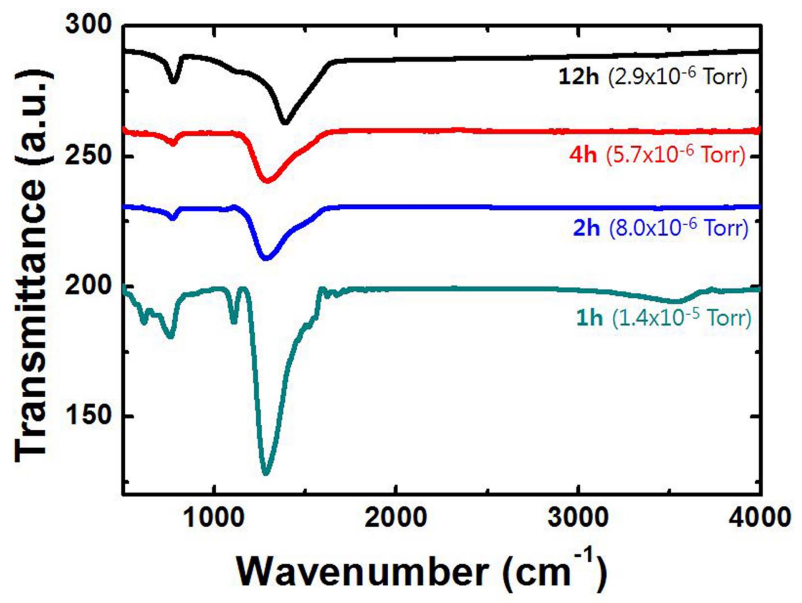

Fig. 2. FTIR spectra of BN films deposited after evacuating for various times. 


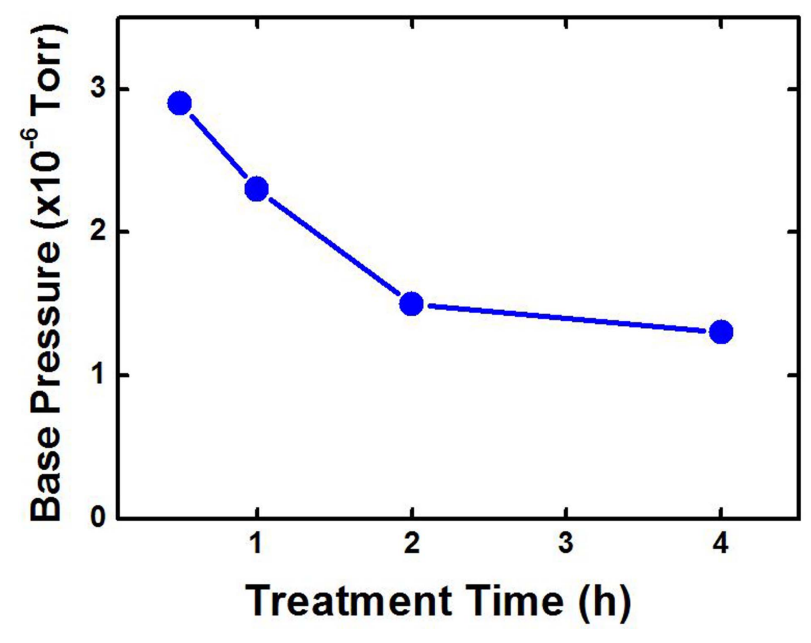

Fig. 3. Variation of chamber pressure according to treatment times of the substrate holder at $250^{\circ} \mathrm{C}$.

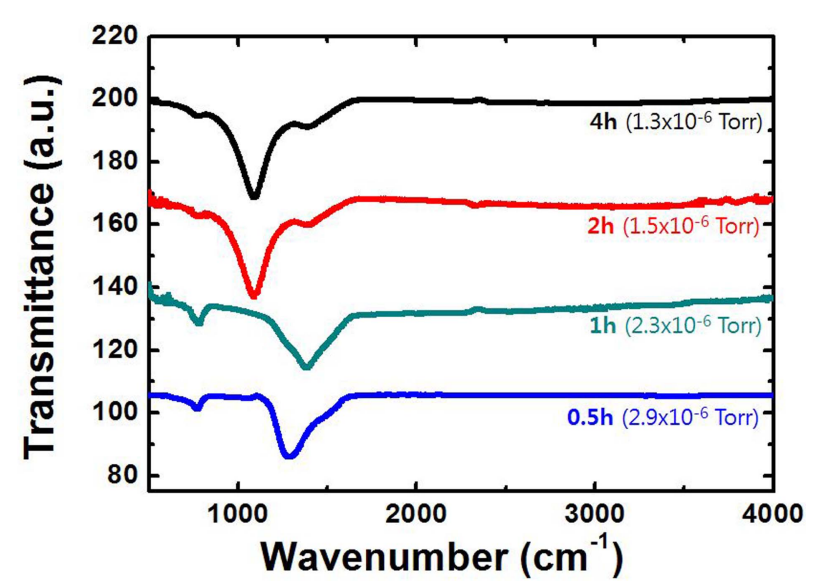

Fig. 4. FTIR spectra of BN films deposited after chamber heating for various times.

의 압력을 보여준다. 고온에서의 유지시간이 길수록 반응 조의 배기 후 압력이 감소함을 볼 수 있고, 유지 초기에 압력의 감소가 현저함을 알 수 있다. 총 배기시간이 현저 히 짧음에도 불구하고 상온에서 배기한 경우(Fig. 2)에 비 해 압력이 크게 감소하였음을 알 수 있다. 따라서 반응조 내벽에 흡착된 수분의 제거를 위해서는 고온에서의 유지 가 매우 효과적임을 알 수 있다.

Fig. 4는 Fig. 3에서 보여준, 각 조건에서 증착시킨 $\mathrm{BN}$ 막의 FTIR 스펙트럼이다. 추가로 30 분간 배기과정이 끝 난 후의 증착 직전의 반응조의 압력을 각 그래프에 표시 하였다. Fig. 6에서 보듯 $250^{\circ} \mathrm{C}$ 에서 두 시간 이상 유지한 경우에 박막은 c-BN 상이 형성되었음을 볼 수 있다. 이 때의 반응조의 압력은 $1.5 \times 10^{-6}$ Torr 이하로 측정되었다. 박 막의 FTIR 스펙트럼을 보면 약간의 h-BN 흡수픽이 보이 고 있는데 c-BN 흡수픽과의 상대강도로 분석한 c-BN 상 의 함량은 약 $77 \%$ 정도이었다.

본 연구에서는 비대칭 마그네트론 스퍼터링 (UBM, Un-

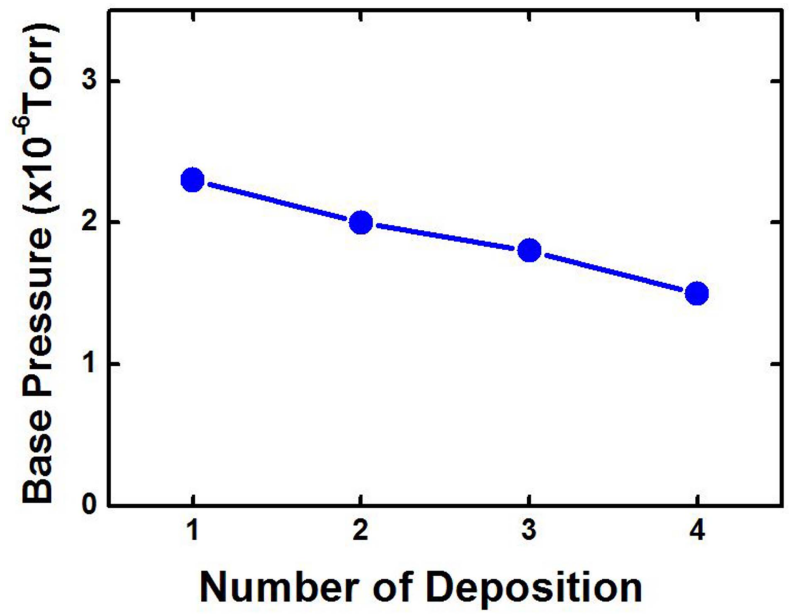

Fig. 5. Variation of chamber pressure according to the number of deposition.

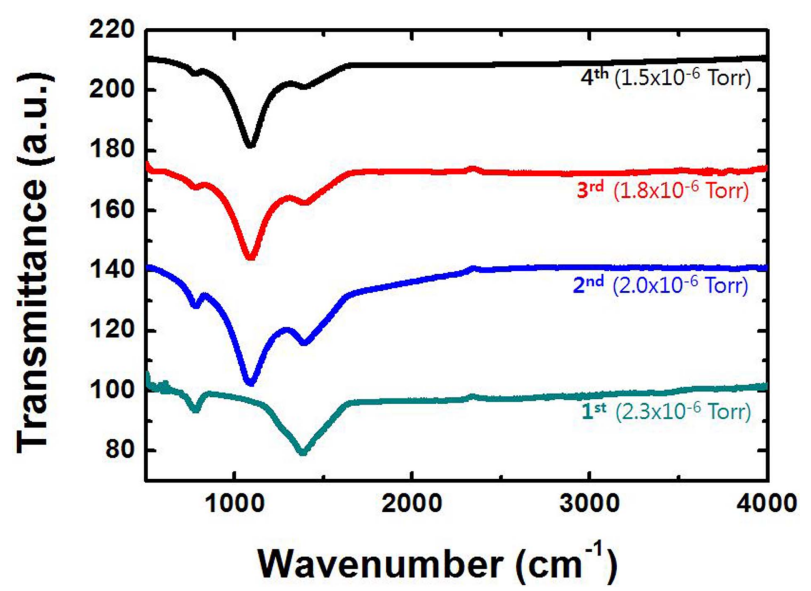

Fig. 6. Variation of FTIR spectrum of BN film according to the repetition numbers of the deposition.

balanced magnetron sputtering) 공정을 사용하였는데, 이 경 우 반응조 내벽은 일반적으로 플라즈마와 접촉이 되게 된 다. 따라서 플라즈마와 반응조 내벽의 반응을 예상할 수 있고, 이러한 반응은 내벽에 흡착된 수분의 탈착에 영향 을 줄 수 있다. 이러한 영향을 보기 위하여 Fig. 4에서 h$\mathrm{BN}$ 상만 형성된 $250^{\circ} \mathrm{C}$ 에서 0.5 시간 유지시킨 조건에서 증착을 반복하여 시도하였다. 증착 중에 플라즈마와 반응 조 내벽이 접촉하게 되므로 증착 수에 비례하여 접촉시 간이 길어지게 된다. Fig. 5는 증착 후 반응조를 30 분간 배기한 후 측정한 반응조의 압력변화이다. 증착횟수가 증 가함에 따라 압력이 감소하는 것이 뚜렷이 관찰되고 있 다. 횟수별로 증착된 $\mathrm{BN}$ 막의 FTIR 스펙트럼은 Fig. 6과 같다. 두 번째 증착부터 c-BN 상이 형성됨을 알 수 있다. 막에 포함된 c-BN상의 함량은 순차적으로 각각, $0 \%, 60 \%$, $73 \%, 76 \%$ 로 분석되었다. 따라서 3 번째 이상부터는 반응 조 내의 분위기에 큰 영향을 받지 않는 것으로 판단 된다. 앞의 결과와 비교하여 보면 반응조의 압력이 최대 


\section{REFERENCES}

\section{4. 결 론}

c-BN 합성에 미치는 반응조 내벽에 흡착된 수분의 영 향을 조사하였다. 반응조 내벽에 흡착된 수분의 제거는 상온에서 진공 펌프를 이용한 단순배기로는 매우 힘든 것 으로 나타났다. 반응조 내벽을 가열하는 방법으로 c-BN 형성에 영향을 주지 않는 정도의 수분의 탈착이 가능한 것으로 관찰되었고, 또한 증착에 사용되는 플라즈마와 반 응조 내벽의 접촉에 의해서도 수분의 탈착이 효율적으로 일어남을 확인하였다. c-BN 상의 합성을 위해서는 반응조 의 압력이 최대한 $2 \times 10^{-6}$ Torr 이하가 되어야 함을 볼 수 있었다. 이러한 결과는 안정한 c-BN 합성을 위한 반응조 의 초기 조건을 설계하는데 유용하게 활용될 수 있을 것 이다. 향후 보다 체계적인 제어를 위해서는 잔류기체 분석 기를 통한 잔류기체의 성분 분석 등을 통한 잔류 수분의 변화 조사 및 제어방법의 모색이 필요할 것으로 생각된다.

\section{Acknowledgment}

본 연구는 지식경제부의 소재원천연구 기술개발사업의 연구비 지원으로 수행되었습니다.
1. L. Vel, G. Demazeau, and J. Etourneau, "Cubic Boron Nitride : Synthesis, Physicochemical Properties and Applications," Mater. Sci. Eng. B, 10 149-64 (1991).

2. P. Widmayer, P. Ziemann, S. Ulrich, and H. Ehrhardt, "Phase Stability and Stress Rlaxation Effects of Cubic Boron Nitride Thin Films Under $350 \mathrm{Kev}$ Ion Irradiation," Dia. Rel. Mater., 6 621-25 (1997).

3. T. A. Friedmann, K. F. McCarty, E. J. Klaus, J. C. Barbour, W. M. Clift, H. A. Johnsen, D. L. Medlin, M. J. Mills, and D. K. Ottesen, "Pulsed Laser Deposition of BN onto Silicon (100) Substrates at $600^{\circ}$ C," Thin Solid Films., 237 48-56 (1994).

4. M. Lattermann, S. Ulrich, and J. Ye, "New Approach in Depositing Thick, Layered Cubic Boron Nitride Coatings by Oxygen Addition - Structural and Compositional Analysis," Thin Solid Films., 515 1058-62 (2006).

5. H.-S. Kim. J.-K. Park, W-.S. Lee, and Y.-J. Baik, "Variation of Residual Stress in Cubic Boron Nitride Film Caused by Hydrogen Addition during Unbalanced Magnetron Sputtering," Thin Solid Films., $5197871-74$ (2011).

6. J. F .O'Hanlon, "A User's Guide to Vacuum Technology," pp. 58, Wiley, New York, 1989.

7. J. Ullmann, J. E. E. Baglin, and A. J. Kellock, "Effect of MeV Ion Irradiation of Thin Cubic Boron Nitride Films," $J$. Appl. Phys., 836 2980-87 (1998). 